\title{
NATURAL SELECTION IN MIXED POPULATIONS OF TWO POLYMORPHIC SNAILS
}

\author{
BRYAN CLARKE \\ Department of Zoology, University Museum, Oxford *
}

Received 6.xi.6I

\section{INTRODUCTION}

Two closely-related species of land snails of the genus Cepaea Held. occur in this country. Both are polymorphic for shell colour and pattern, and their polymorphisms appear to be homologous. Most of the variants found in nature are known to be inherited, the environment having little or no direct effect upon the ornamentation of the shell. The two species are almost identical in form, show a similar range of phenotypes, and seem to share the same predators. Mixed populations occur in some places.

The variation of Cepeae nemoralis $\mathrm{L}$. has been investigated by Cain and Sheppard (1950, 1954, 1957), Cain, King and Sheppard (1960), Schilder (1950), Schnetter (1950) and Lamotte (1951, I954, I959). Cepaea hortensis Mull. has been studied by Schnetter (1950), Lamotte (195I, I959) and Clarke (1960).

Most workers now agree that natural selection plays an important part in determining the distribution of phenotypes within populations of both species. There is still a measure of disagreement, however, about the importance of random processes (Lamotte, I959; Cain and Sheppard, 196I) and about the nature and magnitude of the selective forces acting upon the populations. Very little is known about the way in which the polymorphisms are balanced.

This paper describes a study of the distribution of phenotypes in natural mixed populations of $C$. nemoralis and $C$. hortensis, and attempts an explanation of the mechanisms which maintain their polymorphisms.

\section{METHODS}

\section{(i) Collecting}

During 1957, 1958 and 1959, I collected random samples of C. nemoralis and C. hortensis from forty-six mixed colonies, most of them within sixty miles of Oxford. Localities were selected to include diverse types of vegetation and background. Where possible, several widely separated habitats of the same type were studied. During sampling the areas were searched carefully, to avoid collecting too high a proportion of snails that were obvious to the eye.

\section{(ii) Scoring}

The snails were scored for age, condition (live, dead predated, or dead unpredated), colour, and banding, according to the criteria given in previous publications (Clarke, 1960; Cain and Sheppard, 1950, 1954). In both species the ground colour of the shell is either yellow (grading into white), pink or brown, and there

* Present address : Department of Zoology, West Mains Road, Edinburgh 9. 
may be up to five bands (very rarely six or more) running along the whorl. The bands are usually dark brown in colour. A form of $C$. hortensis in which they are translucent and unpigmented on a pale yellow or white ground colour (var. arenicola MacGillivray) occurs among my collections, usually as a distinct type. In some samples, however, there is a general tendency for the bands to be pale or partially pigmented (var. lurida Moquin-Tandon), and intermediates occur between normal banding and the unpigmented condition. Collections with more than to per cent. of such forms are designated in the tables by an asterisk, but individual shells, unless the bands are completely unpigmented, are scored as normal.

For recording the bands are numbered I, 2, 3, 4 and 5 from the top of the whorl downwards. Absence of a band is recorded by o, and fusions of bands are signified by bracketing the numbers representing the fused bands (e.g. (12) 3(45), I03(45), etc.). A supernumerary band is represented by an $\mathrm{X}$ in the appropriate place (e.g. 12Xo45, г $23 \mathrm{X}(45)$, etc.).

\section{(iii) Classification of habitats}

I have grouped the habitats from which samples were taken into five classes :

(a) Grass. Open habitats in which grass predominates. The background is usually a uniform light green.

(b) Hedgerows and rough herbage. Open habitats in which grass does not predominate. The flora may include nettles (Urtica spp.), brambles (Rubus spp.), willow-herb (Epilobium spp.), ivy (Hedera helix, L.), hawthorn (Crataegus monogyna Jacq.) and various umbellifers. The background is generally darker and less uniform than in the grassy habitats.

(c) Beechwoods. Escarpment woods of pure beech (Fagus sylvatica L.), or beech and ash (Fraxinus excelsior L.). In these habitats there is a layer of leaf litter which gives a dark uniform background.

(d) Other deciduous woods. A heterogeneous class, usually less dark and less uniform than beechwoods.

(e) Fens. The background is usually darker and more uniform than it is among hedgerows and rough herbage, but less so than it is among woods.

Further details of this classification may be found in the earlier paper (Clarke, I960).

Certain unusual habitats demand comment :

(a) Knoll Down. The samples were collected in small beech clumps, each less than a hundred yards across, and each surrounded by downland grass. At Knoll Down B the ground flora within the clump itself is predominantly grass. There is less grass at Knoll Down A.

(b) Roundway Wood. The beech trees are widely spaced, and some grass grows beneath them. The wood is, however, quite extensive (well over a hundred yards in diameter) and is surrounded by mixed vegetation.

(c) Elsfield Covert. The collecting area is damp and boggy, with clumps of Equisetum. The background is unusually dark.

(d) Headington Wick. This fen is in the middle of a wood, where both species occur. The background is a uniform dark brown.

(e) Stanford in the Vale. An unusually dark hedgerow, with a good deal of ivy on the ground.

(f) The Ham. The habitat is now mixed herbage, but was once wooded. The cut stumps of trees remain. There are also ivy and brambles. The background is dark.

\section{THE COMPOSITION OF SAMPLES}

The composition of the samples is given in tables I to 3. Only live and predated (eaten) dead adults are included. Young shells are not recorded in the tables because fusions of bands cannot be 


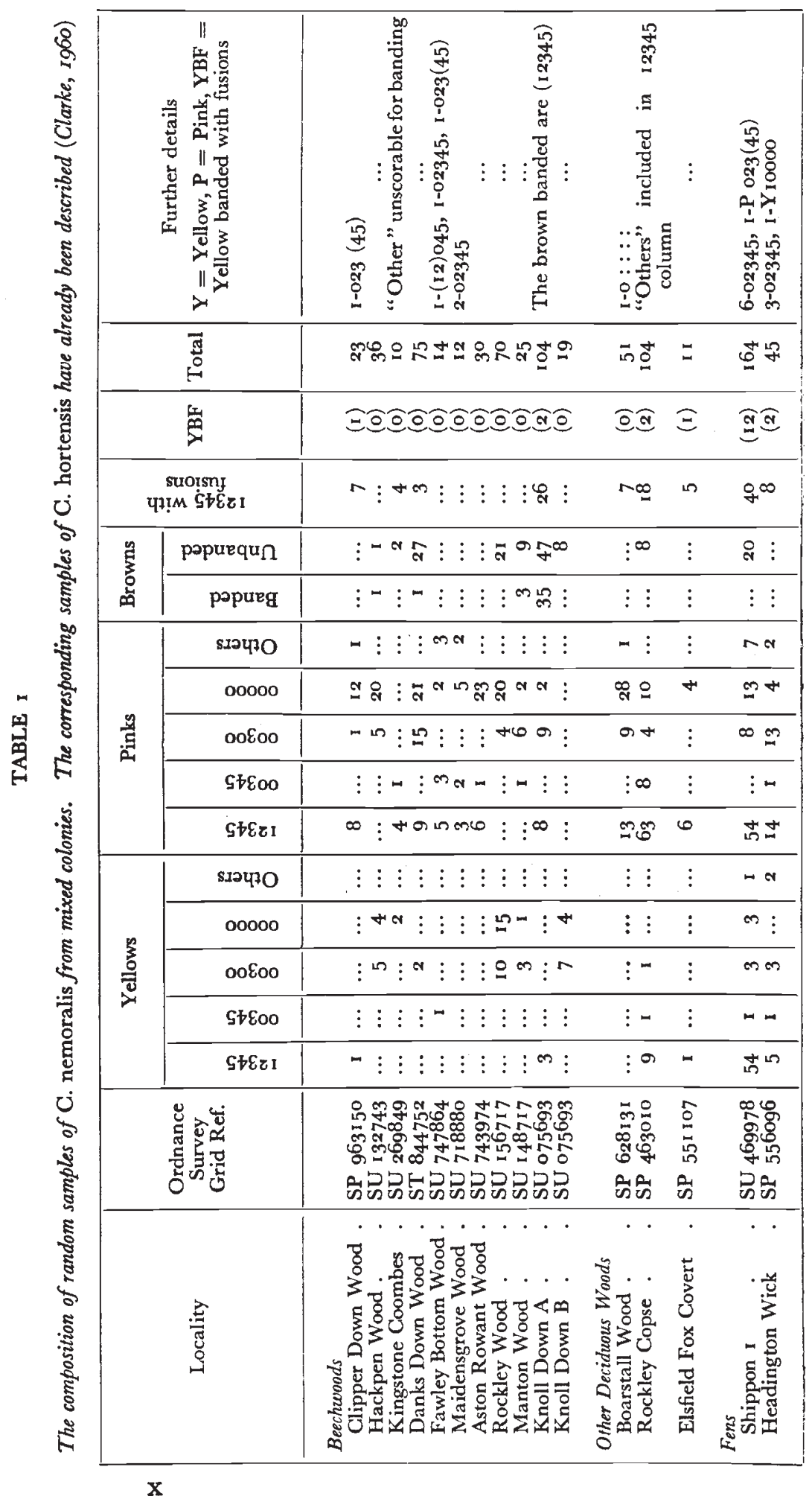


TABLE

The composition of random samples of $\mathrm{C}$. hortensis

\begin{tabular}{|c|c|c|c|c|c|c|c|c|c|c|c|c|}
\hline \multirow{3}{*}{ Locality } & \multirow{3}{*}{$\begin{array}{l}\text { Ordnance } \\
\text { Survey } \\
\text { Grid. Ref }\end{array}$} & \multicolumn{11}{|c|}{ C. hortensis } \\
\hline & & \multicolumn{3}{|c|}{ Yellows } & \multirow{2}{*}{$\begin{array}{l}8 \\
8 \\
\vdots \\
\text { : }\end{array}$} & \multicolumn{2}{|c|}{ A } & \multirow{2}{*}{ 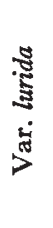 } & \multirow{2}{*}{ 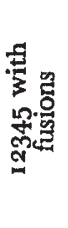 } & \multirow[b]{2}{*}{ YBF } & \multirow[b]{2}{*}{ 吾 } & \multirow[b]{2}{*}{ Comments } \\
\hline & & ڤै & 8 & 题 & & 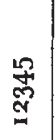 & 总 & & & & & \\
\hline $\begin{array}{l}\text { Beechwood } \\
\text { Roundway Wood }\end{array}$ & SU or 3639 & 9 & $\cdots$ & 10 & $\cdots$ & $\cdots$ & $\cdots$ & $\cdots$ & $\cdots$ & (o) & 19 & $\begin{array}{l}\mathrm{A}=\mathrm{var} . \\
\text { arenicola } \\
\mathrm{I}-\mathrm{I} 0005 \\
\mathrm{I}-\mathrm{I} 0045 \\
6-10345 \\
\mathrm{I}-\mathrm{r} 2045 \\
\mathrm{I}-\mathrm{I} 20(45)\end{array}$ \\
\hline $\begin{array}{l}\text { Other Deciduous } \\
\text { Wood } \\
\text { Uffington Wood } 2\end{array}$ & SU 304868 & 16 & I & $\cdots$ & $\cdots$ & 4 & $\cdots$ & * & 6 & (6) & $2 \mathrm{I}$ & $\begin{array}{l}*=\text { more } \\
\text { than I0\% } \\
\text { var. lurida } \\
\text { in sample }\end{array}$ \\
\hline $\begin{array}{l}\text { Fens } \\
\text { Cothill Fen } \\
\text { Shippon Fen } 2 .\end{array}$ & $\begin{array}{l}\text { SU } 463997 \\
\text { SU } 46997^{8}\end{array}$ & $\begin{array}{r}8 \\
68\end{array}$ & $\begin{array}{r}5 \\
59\end{array}$ & $\cdots$ & $\begin{array}{r}6 \\
26\end{array}$ & $\begin{array}{l}\cdots \\
\cdots\end{array}$ & $\begin{array}{l}\cdots \\
\cdots\end{array}$ & $\begin{array}{l}\cdots \\
\cdots\end{array}$ & $\cdots$ & $\begin{array}{l}(0) \\
(3)\end{array}$ & $\begin{array}{r}19 \\
153\end{array}$ & $\begin{array}{l}\text { Pinks have } \\
\text { black lips }\end{array}$ \\
\hline $\begin{array}{l}\text { Hedgerows and } \\
\text { Rough Herbage }\end{array}$ & & & & & & & & & & & & $\mathrm{Y}=$ Yellow \\
\hline $\begin{array}{l}\text { Hatford } \\
\text { Shepherd's Rest I }\end{array}$ & $\begin{array}{l}\text { SU } 34695^{\mathrm{I}} \\
\text { SU } 222808\end{array}$ & $\begin{array}{c}8 \\
156\end{array}$ & $\begin{array}{r}1 \\
34\end{array}$ & $\dddot{1} 8$ & $\begin{array}{l}\cdots \\
\cdots\end{array}$ & $\begin{array}{c}3 \\
14\end{array}$ & $\begin{array}{r}\cdots \\
5\end{array}$ & $\dddot{*}$ & $8^{I}$ & $\begin{array}{l}(1) \\
(7)\end{array}$ & $\begin{array}{r}12 \\
227\end{array}$ & $\begin{array}{r}17-Y_{10345} \\
1-Y_{12045} \\
5-A 10345\end{array}$ \\
\hline Shepherd's Rest 2 & SU 219807 & I9 & $\cdots$ & $\cdots$ & $\cdots$ & $\cdots$ & $\cdots$ & $*$ & $\cdots$ & (o) & 19 & $\ldots$ \\
\hline $\begin{array}{l}\text { Stanford in the } \\
\text { Vale }\end{array}$ & SU $33593^{6}$ & 44 & 14 & $\cdots$ & $\ldots$ & $\cdots$ & $\cdots$ & $\cdots$ & 26 & (26) & 58 & $\cdots$ \\
\hline Wooton . & SP 468012 & 14 & 13 & $\cdots$ & 9 & $\cdots$ & $\cdots$ & $\cdots$ & I & (I) & 36 & $\begin{array}{c}\text { Pinks have } \\
\text { black lips }\end{array}$ \\
\hline $\begin{array}{l}\text { Chisledon. } \\
\text { Faringdon } \\
\text { The Ham . } \\
\text { Wanborough Plain }\end{array}$ & $\begin{array}{l}\text { SU } 180799 \\
\text { SU } 317971 \\
\text { SU } 388874 \\
\text { SU } 244798\end{array}$ & \begin{tabular}{|r|}
167 \\
99 \\
20 \\
20
\end{tabular} & $\begin{array}{c}121 \\
84 \\
16 \\
\cdots\end{array}$ & $\begin{array}{c}\cdots \\
\cdots \\
\cdots \\
3\end{array}$ & $\begin{array}{l}\ldots \\
\cdots \\
\cdots \\
\cdots\end{array}$ & $\begin{array}{l}6 \\
\cdots \\
\cdots \\
27\end{array}$ & $\begin{array}{c}\ldots \\
\cdots \\
\cdots \\
3\end{array}$ & $\begin{array}{l}* \\
\cdots \\
\cdots\end{array}$ & $\begin{array}{r}48 \\
21 \\
12 \\
1\end{array}$ & $\begin{array}{r}(48) \\
(21) \\
12) \\
(1)\end{array}$ & $\begin{array}{r}294 \\
183 \\
36 \\
53\end{array}$ & $\begin{array}{c}\cdots \\
\cdots \\
\cdots \\
6-10345\end{array}$ \\
\hline Watchfield & SU 2559 I I & 4 & 12 & $\ldots$ & $\ldots$ & $\cdots$ & $\ldots$ & $\cdots$ & & (o) & I6 & .. \\
\hline Hill Barn Tumulus & SU 3 & 9 & $\ldots$ & I & $\ldots$ & 6 & $\ldots$ & $*$ & (2) & (2) & I6 & $1-02345$ \\
\hline Little Hinton & SU $224^{823}$ & 39 & 12 & I & $\cdots$ & 9 & $\cdots$ & $*$ & 8 & (7) & $6 r$ & $1-10345$ \\
\hline
\end{tabular}


and $\mathrm{C}$. nemoralis from mixed colonies

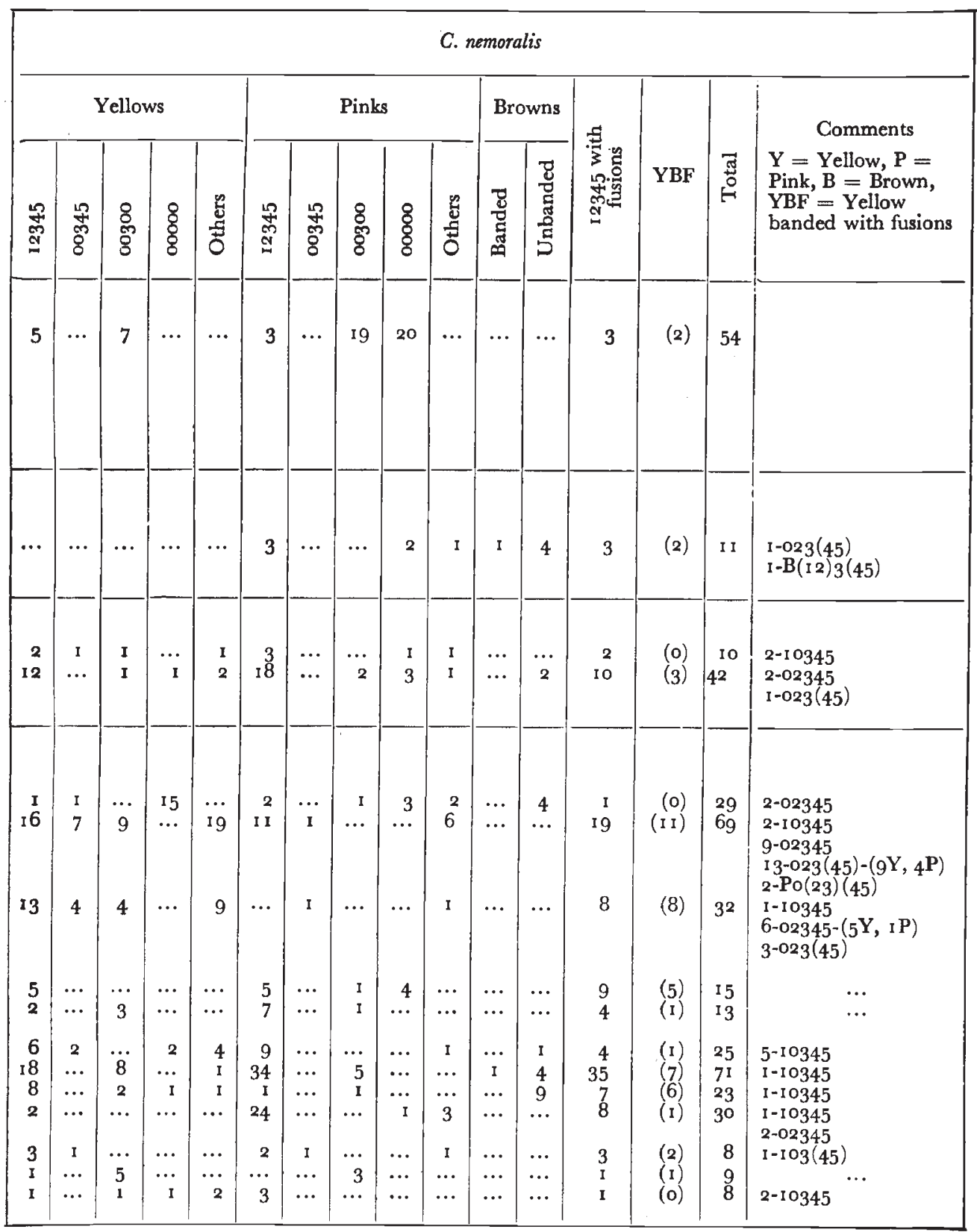


TABLE

The composition of random samples of $\mathrm{C}$. hortensis

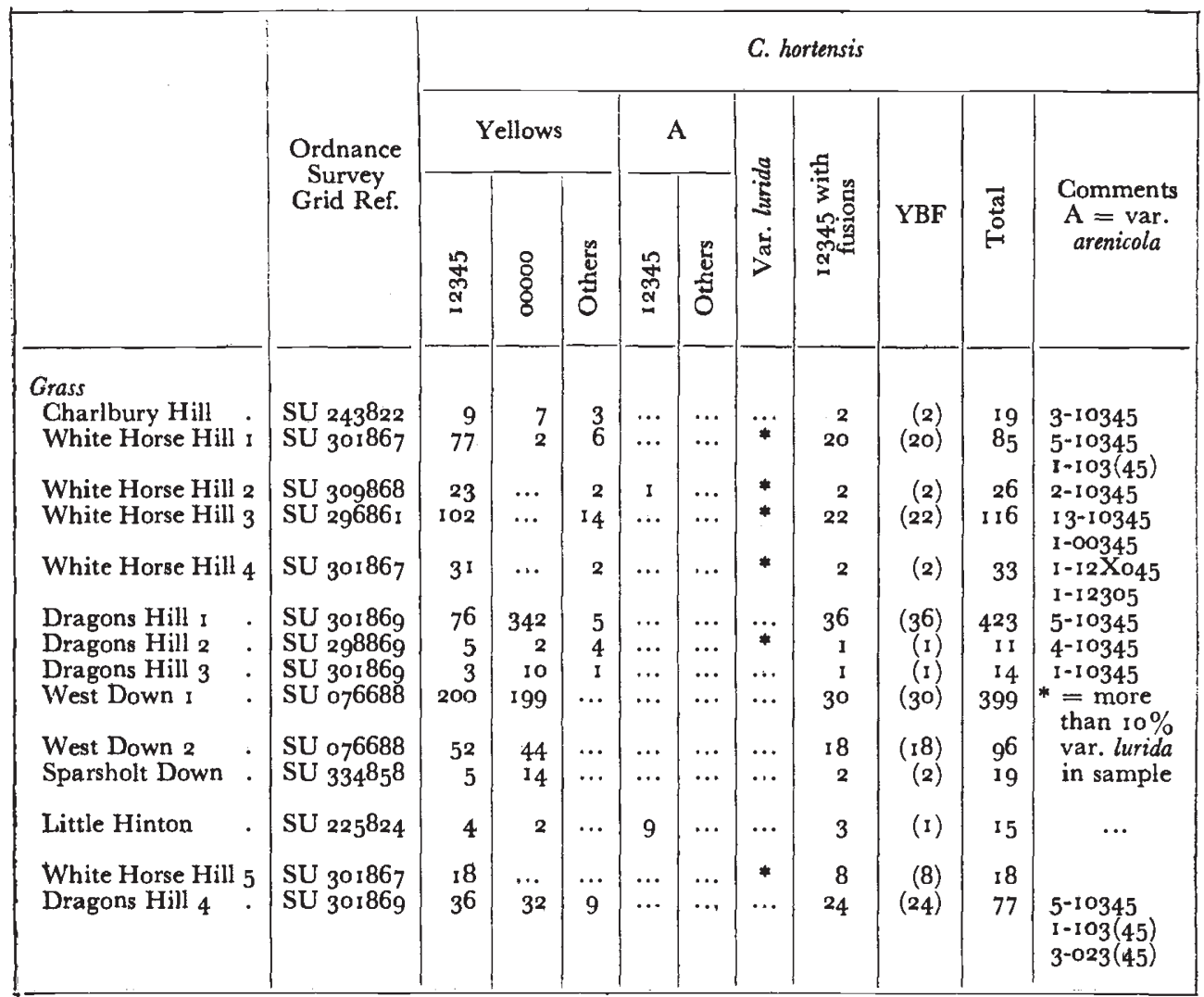

scored among them. Unbroken dead adults are excluded because the mode of death is not known, and therefore the direction of possible errors cannot be predicted (Clarke, 1960).

Table I gives details of collections of $C$. nemoralis from localities whose populations of hortensis have already been described (Clarke, 1960). Tables 2 and 3 record the composition of samples from other mixed colonies.

When analysing the collections, I have worked out the frequencies of various phenotypes, and groups of phenotypes, for each species separately. This has been done because the relative proportions of the two species cannot be estimated accurately (see below). For each species in every sample the following values have been computed:

(a) The percentage of yellow $(\mathrm{Y})$ shells.

(b) The percentage of "effectively yellow" (EY) shells. This class includes all shells whose ground-colour is yellow, except those which are five-banded and which have two or more of the bands fused together. The fusion of bands tends to obscure the groundcolour of the shell. 
and $\mathrm{C}$. nemoralis from mixed colonies

\begin{tabular}{|c|c|c|c|c|c|c|c|c|c|c|c|c|c|c|c|}
\hline \multicolumn{16}{|c|}{ C. nemoralis } \\
\hline \multicolumn{5}{|c|}{ Yellows } & \multicolumn{5}{|c|}{ Pinks } & \multicolumn{2}{|c|}{ Browns } & \multirow{2}{*}{ 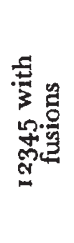 } & \multirow[b]{2}{*}{ YBF } & \multirow[b]{2}{*}{ 莒 } & \multirow{2}{*}{$\begin{array}{c}\text { Comments } \\
\mathrm{Y}=\text { Yellow, } \mathrm{B}= \\
\text { Brown, } \mathrm{P}=\text { Pink }\end{array}$} \\
\hline 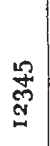 & ఫ్ & $\stackrel{\circ}{\circ}$ & $\begin{array}{l}8 \\
\$\end{array}$ & 总 & 㤀 & ఫ్ & 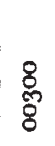 & 8 & 总 & 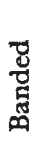 & 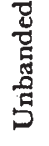 & & & & \\
\hline 2 & $\ldots$ & 5 & I & $\ldots$ & 1 & $\ldots$ & 4 & 7 & $\ldots$ & $\ldots$ & 5 & 1 & (o) & 25 & \\
\hline 4 & 10 & 4 & $\cdots$ & 3 & 3 & 3 & 7 & $\cdots$ & 1 & 2 & 1 & 4 & (3) & $3^{8}$ & $4^{-02345}$ \\
\hline 6 & 6 & 10 & $\ldots$ & $\ldots$ & $\ldots$ & $\ldots$ & $\ldots$ & $\ldots$ & $\ldots$ & $\ldots$ & $\ldots$ & 2 & (2) & 22 & \\
\hline 7 & 2 & 12 & $\cdots$ & 7 & 7 & 4 & 5 & $\ldots$ & 2 & $\cdots$ & $\ldots$ & 6 & (2) & 47 & $\underset{1-02345}{7-02 \mathrm{Y}, 2 \mathrm{P})}$ \\
\hline 7 & $\cdots$ & 2 & $\cdots$ & 2 & $\cdots$ & 1 & 1 & $\therefore$ & $\cdots$ & $\cdots$ & $\cdots$ & 5 & (5) & 13 & $2-02345$ \\
\hline 2 & 4 & 5 & ... & $\ldots$ & 3 & 4 & 19 & $\ldots$ & 5 & 2 & 4 & 3 & (2) & 48 & $8-023(45)$ \\
\hline 1 & I & 6 & $\ldots$ & $\ldots$ & $\ldots$ & I & 4 & $\ldots$ & $\ldots$ & 2 & 2 & I & (1) & 17 & \\
\hline 1 & 2 & 3 & $\ldots$ & 2 & 2 & 3 & 12 & $\cdots$ & 1 & $\ldots$ & 4 & I & (1) & 30 & $1.023(45)$ \\
\hline$\cdots$ & I & 4 & 3 & 1 & $\cdots$ & $\cdots$ & $\cdots$ & $\cdots$ & $\cdots$ & 7 & 2 & I & (o) & 18 & $1-Y 10345$ \\
\hline$\ldots$ & $\ldots$ & 5 & 3 & $\ldots$ & $\ldots$ & $\ldots$ & $\ldots$ & 1 & 1 & $\ldots$ & 5 & $\ldots$ & (o) & 15 & $\mathrm{I}-10345$ \\
\hline 13 & I & 15 & $\cdots$ & 6 & $\cdots$ & $\cdots$ & $\cdots$ & $\cdots$ & $\cdots$ & $\cdots$ & $\cdots$ & 4 & (4) & 35 & 2-02345 \\
\hline 5 & $\cdots$ & 1 & .. & 5 & 5 & $\cdots$ & 1 & 3 & 1 & $\cdots$ & $\cdots$ & 4 & (2) & 21 & $\begin{array}{l}4-Y 10345 \\
5-Y 1034(4) \\
1-P 023(45)\end{array}$ \\
\hline$\ldots$ & 2 & 2 & $\ldots$ & $\ldots$ & 1 & $\ldots$ & 1 & $\ldots$ & 1 & 1 & $\ldots$ & $\cdots$ & (o) & 8 & $\mathrm{I}-023(45)$ \\
\hline 1 & $\ldots$ & 2 & $\ldots$ & 2 & 1 & $I$ & 6 & I & 2 & $\ldots$ & 1 & 2 & (2) & 17 & $2-023(45)$ \\
\hline
\end{tabular}

(c) The percentage of unbanded (ooooo) shells.

(d) The percentage of yellow unbanded (Yoooo) shells.

(e) The percentage of "effectively unbanded" (EU) shells. This class includes albinos, and all shells that have the two top bands missing (e.g. 00300, 00345, 00045, etc., as well as 0000o). shells.

$(f)$ The percentage of yellow "effectively unbanded" (YEU)

$(g)$ The percentage of yellow " effectively banded" (YEB) shells. This class includes all four- and five-banded shells without fusions, and also (arbitrarily) four-banded shells with fusions of the lower two bands. The last forms are rare:

(h) The percentage of yellow five-banded shells that have two or more bands fused together (YBF).

(i) The number of five-banded shells that have two or more bands fused together, expressed as a percentage of the total number of five-banded shells within the species $(\mathrm{F})$.

It is worth noting that category $(b)$ is equal to the sum of categories $(f)$ and $(g)$, and to the difference between categories $(a)$ and $(h)$ 
(i.e. per cent. $\mathrm{EY}=$ per cent. $\mathrm{YEU}+$ per cent. $\mathrm{YEB}=$ per cent. $\mathrm{Y}-$ per cent. YBF).

The rationale of these categories will be discussed below.

\section{RELIABILITY OF SAMPLING}

Some idea of the reliability of the sampling methods can be obtained by comparing successive samples of live individuals taken from the same locality, and also by comparing live and predated (eaten) material.

Tables 4 and 5 compare successive collections of live snails from particular localities. Table 4 deals with samples of $C$. hortensis from localities which have not already been analysed in an earlier publication (Clarke, 1960). Table 5 deals with samples of $C$. nemoralis. The tables show that successive collections from the same locality do not differ significantly from each other.

TABLE 4

G. hortensis. Comparison of samples taken from the same places at different times. Other such comparisons have been made in an earlier publication (Clarke, rg6o)

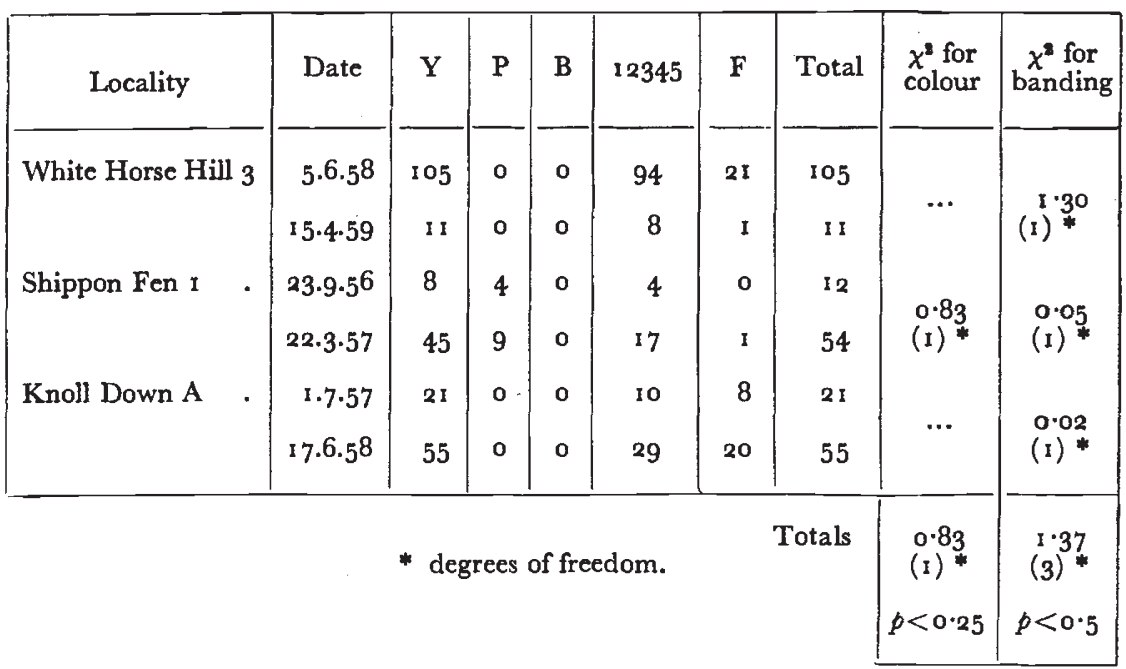

Table 6 compares the proportions of the two species in successive samples. It shows highly significant differences between them $(p<0 \cdot 001)$.

Comparisons of live and predated material give similar results. There were no significant differences in phenotype-frequency between live and thrush-predated adults in either species (the samples were not large enough to detect even quite strong visual selection by the birds). There were, however, differences in the proportions of the species themselves. These deviations were not consistent in direction, and provided no evidence that thrushes always preferred one species 
TABLE 5

G. nemoralis. Comparison of samples taken from the same places at different times. In calculating the $x^{2}$ for Dragons Hill 1, yellows and browns have been grouped together

\begin{tabular}{|c|c|c|c|c|c|c|c|c|c|}
\hline Locality & Date & $\mathbf{Y}$ & $\mathrm{P}$ & $\mathrm{B}$ & 12345 & $\mathbf{F}$ & Total & $\begin{array}{l}\chi^{2} \text { for } \\
\text { colour }\end{array}$ & $\begin{array}{c}\chi^{2} \text { for } \\
\text { banding }\end{array}$ \\
\hline \multirow[t]{2}{*}{ White Horse Hill I } & $16.4 .5^{8}$ & 13 & 10 & 3 & 8 & 3 & 26 & & \\
\hline & 15.4 .59 & 8 & 4 & 0 & 1 & 1 & 12 & $\begin{array}{l}0.37 \\
(1)^{*}\end{array}$ & $(1)^{1 \cdot 21}$ \\
\hline \multirow[t]{2}{*}{ White Horse Hill 3} & $5.6 .5^{8}$ & 19 & 12 & 0 & 9 & 4 & 31 & & \\
\hline & $15 \cdot 4.59$ & Io & 6 & o & 5 & 2 & 16 & (1) * & (1) * \\
\hline \multirow[t]{2}{*}{ Dragons Hill $\mathrm{I}$} & 1956 & 1 & 8 & 1 & 0 & o & 10 & & \\
\hline & $\begin{array}{c}1957 \\
1958-59\end{array}$ & $\begin{array}{l}5 \\
1\end{array}$ & $\begin{array}{l}5 \\
9\end{array}$ & $\begin{array}{l}2 \\
1\end{array}$ & $\begin{array}{l}1 \\
0\end{array}$ & $\begin{array}{l}1 \\
0\end{array}$ & $\begin{array}{l}12 \\
11\end{array}$ & $\begin{array}{l}5 \cdot 31 \\
(2)^{*}\end{array}$ & $\cdots$ \\
\hline \multirow[t]{2}{*}{ Knoll Down A } & 1.7 .57 & o & 4 & 24 & 7 & 6 & 28 & & \\
\hline & ${ }_{17.6 .58}$ & 3 & 15 & $5^{8}$ & 26 & 26 & 76 & $(1)^{*}$ & $(1)^{*}$ \\
\hline \multicolumn{8}{|c|}{ * degrees of freedom. } & $\begin{array}{c}6 \cdot 33 \\
(5)^{*} \\
p<0 \cdot 25\end{array}$ & $\begin{array}{c}1.67 \\
(3)^{*} \\
p<0.5\end{array}$ \\
\hline
\end{tabular}

TABLE 6

Comparison of the proportions of the two species in samples taken from the same places at different times. In calculating the $x^{2}$ for Dragons Hill 1 , all the samples collected in 1957 have been grouped together

\begin{tabular}{|c|c|c|c|c|c|c|c|}
\hline Locality & Date & C. hort. & C. nem. & Total & $\chi^{2}$ & d.f. & $p$ \\
\hline White Horse Hill I & $\begin{array}{l}16.4 .5^{8} \\
15.4 .59\end{array}$ & $\begin{array}{l}33 \\
5^{2}\end{array}$ & $\begin{array}{l}26 \\
12\end{array}$ & $\begin{array}{l}59 \\
64\end{array}$ & $8 \cdot 07$ & 1 & $p<0.005$ \\
\hline White Horse Hill 3 & $\begin{array}{r}5.6 .58 \\
15.4 .59\end{array}$ & $\begin{array}{r}105 \\
11\end{array}$ & $\begin{array}{l}31 \\
16\end{array}$ & $\begin{array}{r}136 \\
27\end{array}$ & $12 \cdot 88$ & 1 & $p<0.001$ \\
\hline Dragons Hill I & $\begin{array}{l}16.9 .56 \\
16.4 \cdot 57 \\
16.4 .57 \\
12.6 .57 \\
16.4 .58 \\
15.4 .59\end{array}$ & $\begin{array}{r}169 \\
37 \\
17 \\
24 \\
34 \\
43\end{array}$ & $\begin{array}{r}10 \\
3 \\
9 \\
0 \\
5 \\
6\end{array}$ & $\left.\begin{array}{c}179 \\
40 \\
26 \\
24 \\
39 \\
49\end{array}\right\}$ & $5 \cdot 79$ & 3 & $p<0.25$ \\
\hline Shippon Fen I & $\begin{array}{r}23.9 \cdot 56 \\
22.3 \cdot 57\end{array}$ & $\begin{array}{l}12 \\
54\end{array}$ & $\begin{array}{l}3 \\
5\end{array}$ & $\begin{array}{l}15 \\
59\end{array}$ & $\cdots$ & $\cdots$ & $\cdots$ \\
\hline Knoll Down A & $\begin{array}{r}1.7 .57 \\
17.6 .58\end{array}$ & $\begin{array}{l}21 \\
55\end{array}$ & $\begin{array}{l}28 \\
76\end{array}$ & $\begin{array}{r}49 \\
131\end{array}$ & 0.004 & I & $p<0.95$ \\
\hline \multicolumn{5}{|c|}{ Total } & $26 \cdot 74$ & 6 & $p<0.001$ \\
\hline
\end{tabular}


to another. It is likely that the two snails are most active (and obvious) at different times and under different conditions.

It is worth noting in this context that some localities show drastic and significant changes in the proportions of the two species over very short distances (five yards or less). Sedlmair (1956) has reported differences of behaviour between the two snails under controlled conditions of temperature and humidity. Evidently, the relative abundance of nemoralis and hortensis at any locality cannot be assessed reliably from a single sample. It seems, however, that the samples give valid estimates of phenotype-frequencies within species (see also Clarke, I96o; Clarke and Murray, in press).

\section{THE DISTRIBUTION OF PHENOTYPES WITHIN INDIVIDUAL SPECIES}

If the samples of hortensis are compared with those of nemoralis it can be seen that there are profound differences between them in the distribution of various phenotypes. Tables I to 3 show that although the two species have manyvarieties in common, the frequencies of these varieties are by no means similar. In hortensis, yellow shells almost invariably predominate; in nemoralis, pinks and browns are often more common. Albino shells and pale-banded forms occur much more frequently in hortensis than they do in nemoralis. Shells with the first two bands missing (i.e. 00345, 00045, 0030o, etc.) are much commoner in nemoralis. These observations agree with the earlier statements of Taylor (I9I4), Cain and Sheppard (I954) and Clarke (ig6o).

Cain and Sheppard (I950, I954) have demonstrated that the frequencies of various phenotypes in populations of $C$. nemoralis can be related to the type of habitat in which they occur. Generally speaking, the commonest varieties are those which most nearly match the background of the habitat. Thus in beechwoods, pink and brown unbanded shells are common. These approximately resemble the layer of dark leaf-litter in which they live. Grasslands and rough herbages, on the other hand, show a high proportion of yellow shells. Visually uniform habitats usually support a higher frequency of " effectively unbanded" shells while in habitats with a mixed or stripy background banded shells are more common. Cain and Sheppard explain these relations (although not the maintenance of the polymorphism itself) in terms of selective visual predation, which has been demonstrated by Sheppard (I95I). Thrushes, the predators studied by Sheppard, apparently kill a larger proportion of those snails whose colour or pattern stands out against the visual background of the habitat, and a smaller proportion of those which most nearly resemble it.

In an earlier paper (Clarke, I960), I have shown that in $C$. hortensis also there is a relation between the distribution of phenotypes and the nature of the habitat. It is remarkable that, despite an 
apparently homologous polymorphism, hortensis responds in a very different way. In beechwoods this species shows a high proportion, not of browns and pinks, but of yellows. These, however, tend to be almost entirely banded, with many of the bands fused together giving an overall brown appearance (except at the edges of the whorl where the yellow colour shows through). In mixed herbage, as with nemoralis, there are many yellow banded shells without fusions, and in uniform green grass the proportion of yellow unbanded shells is usually

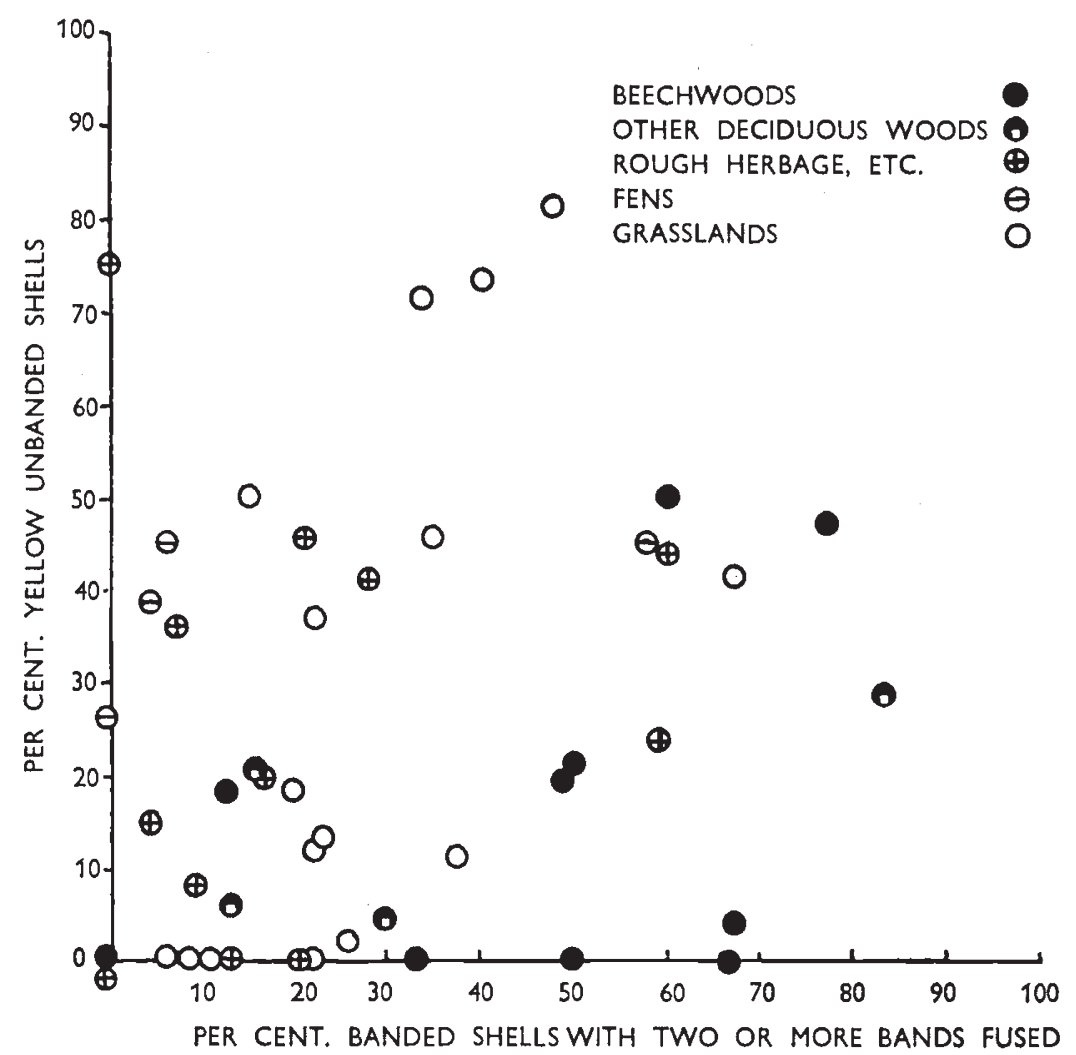

FIG. 1.-A scatter-diagram showing the distribution of two groups of phenotypes in random samples of Cepaea hortensis Mull. from mixed colonies. The separation between different classes of habitat is statistically significant on both axes.

relatively high. I have argued that these results once again suggest the influence of visual predators but that the response is different because pink and brown hortensis are at a selective disadvantage in nearly all habitats, probably for reasons that have little or nothing to do with the visible properties of the shells.

The data given in tables $I$ to 3 confirm and extend the earlier results. Fig. $I$ is a scatter-diagram showing the distribution of two classes of phenotype in the samples of $C$. hortensis from mixed colonies. Each spot represents a single population. The position of a spot on the vertical axis is determined by the percentage of yellow unbanded 
shells. Along the horizontal axis its position is determined by the proportion of five-banded shells that have two or more bands fused together (expressed as a percentage of the total number of five-banded shells in this species). The figure corresponds to one given in the earlier paper (Clarke, r96o, fig. 4) and there is substantial agreement between them. It must be noted that a number of colonies (those given in table I) are recorded on both figures. Once again, however, colonies from each class of habitat tend to fall into a group. The separation is significant on both axes $(p<0 \cdot 0 \mathrm{I})$.

A number of colonies that appear, on the evidence of their position on fig. I, to be aberrant, do in fact come from unusual habitats. The beechwoods Knoll Down A and B have an unusually high proportion of yellow unbanded shells, but, as I have already mentioned, they are very grassy, and the background in places is almost green (particularly at Knoll Down B). Roundway Wood, which has no yellow unbanded shells and no fusions, is also grassy. It can be seen from table 2, however, that the majority of the banded forms lack one or more bands. In this respect Roundway is unique among the woods studied. Headington Wick, which has more fusions than the other fens, lies in the centre of a wood. Stanford in the Vale and the Ham, which also display unusually high frequencies of fusions, are both darker than most other open habitats.

There is a group of grasslands, hedgerows and rough herbages in which the frequencies of yellow unbanded shells are particularly low when considered in relation to the background. It is remarkable that within this group are found modifications resulting in the reduction of visible banding. These modifications do not usually occur in samples from other open habitats.

There are three types of band reduction in hortensis:

(i) The "albino" condition (var. arenicola MacGillivray) in which bands are present but unpigmented.

(ii) The "pale-banded" condition (var. lurida Moquin-Tandon) in which the band pigment is diluted.

(iii) The loss of bands (usually the second or third band, giving rise to such forms as 10045, 10345, I 2045, etc.).

If the shell is albino and the pigmentation of the body is pale (as is usual in $C$. hortensis) the bands are almost completely invisible. Albino shells can therefore be regarded as yellow "effectively unbanded" and classed with those which are truly unbanded. In fig. 2 the frequency of this new category is plotted along the vertical axis. It can be seen that there is a better vertical separation between habitat classes than there is in fig. I.

It is virtually impossible to give an objective estimate of the extent of band reduction brought about by the pale-banded condition. All sorts of intermediates occur. Nevertheless it can hardly be a coincidence that the six grassland samples which have the lowest proportion of yellow effectively unbanded shells all display a tendency to 
"pale-bandedness", whereas none of the eight other grassland samples do so. Among the hedgerows and rough herbages there are two samples with an unusually low proportion of yellow effectively unbanded shells (Shepherd's Rest I and 2). Both tend towards " pale-banded ness ". Of the remaining ten samples from open habitats, four do so. If a median line is drawn across the vertical axis of fig. 2 so as to divide the grasslands, hedgerows and rough herbages into two groups of equal size, it is found that among the lower thirteen samples there

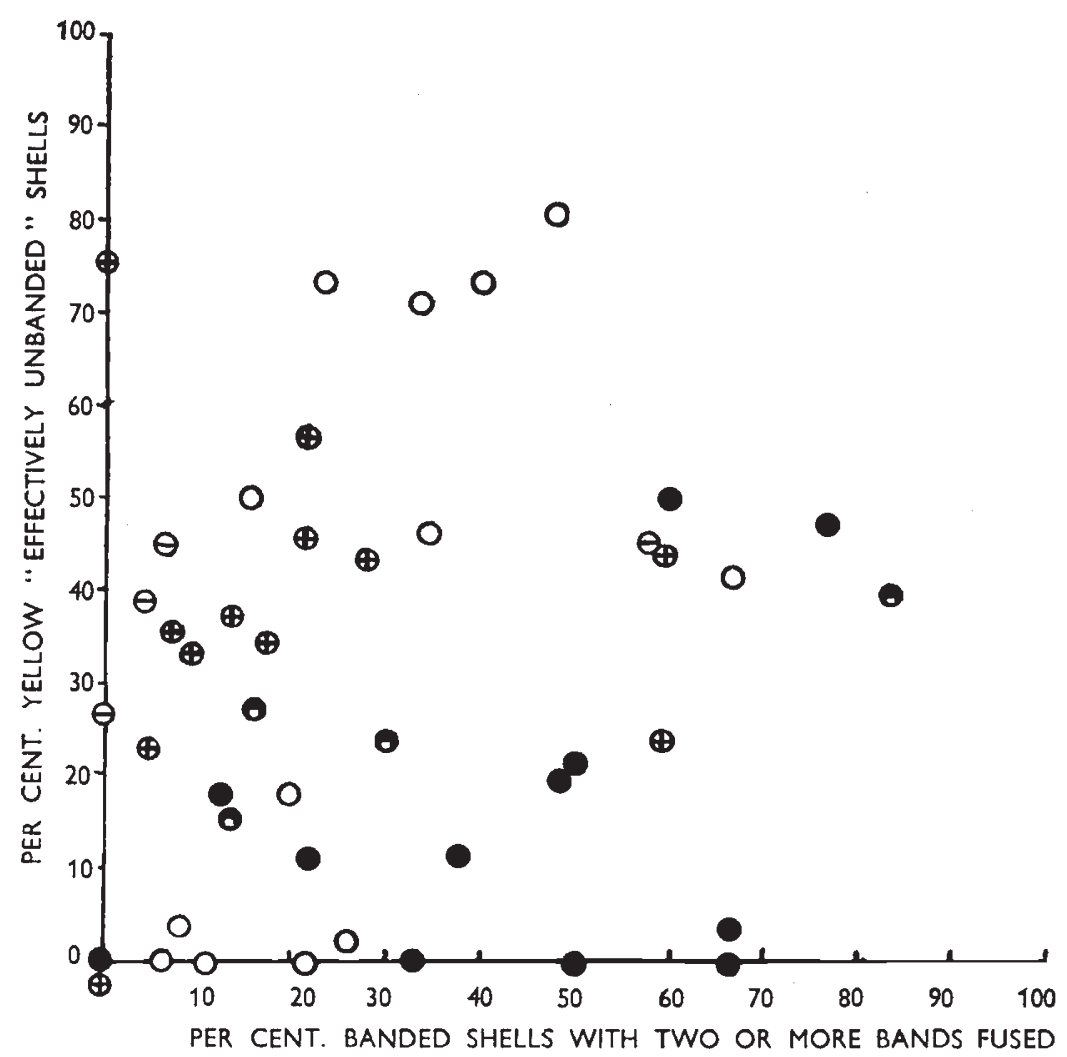

FIG. 2.-A scatter-diagram for $C$. hortensis showing the relation between the percentage of yellow "effectively unbanded" shells, the percentage of banded shells with fused bands (see text) and the nature of the habitat. The separation between different classes of habitat is clearer than it is on fig. 1. Symbols as in fig. 1.

are nine showing the pale-banded condition. Among the upper thirteen samples only three show it. The difference is statistically significant $(p<0.05)$ even if the darkness of the background at Stanford in the Vale is not takent into account. The rarity of pale-banded forms in the upper group is not due merely to the low frequency of any forms of banding. If all samples with less than ten banded shells are excluded, then the numbers of banded shells in the two groups become comparable, and the difference remains significant. Additional data, from localities in which hortensis occurs alone, confirm these 
observations (Clarke, in preparation). This is regarded as additional evidence of the selective importance of visible shell characters (see below).

Fig. 3 is a scatter-diagram showing the distribution of two classes of phenotypes in my samples of Cepaea nemoralis from mixed colonies. It is drawn in the same way as that given by Cain and Sheppard (1954, fig. I). Along the vertical axis are plotted the percentages of yellow shells. The horizontal axis gives the frequency of " effectively

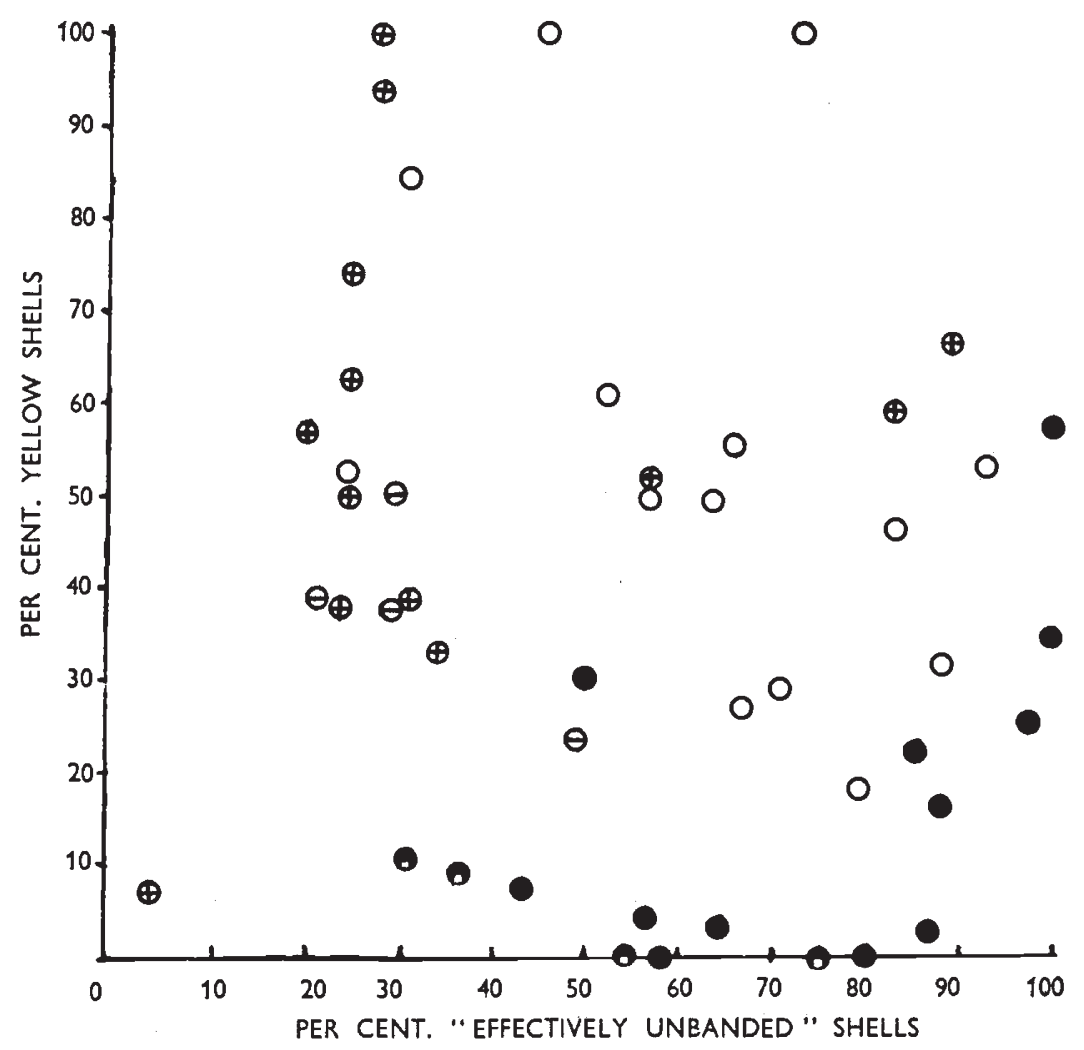

Fro. 3.-A scatter-diagram showing the distribution of two groups of phenotypes in random samples of Cepaea nemoralis $\mathrm{L}$. from mixed colonies. Symbols as in fig. 1 . Once again there is a clear separation between different classes of habitat.

unbanded" forms (regardless of colour). Once again, as in Cain and Sheppard's figure, samples from similar habitats tend to be grouped together. The separation is significant $(p<0.001)$ on the vertical axis, but not quite significant $(p<0 \cdot I)$ on the horizontal.

There are certain differences between fig. 3 and the scatter-diagram given by Cain and Sheppard. Knoll Down B, as might be expected, shows an unusually high proportion of yellows. Knoll Down A, however, does not. It must be noted that the Knoll Down localities are surrounded by downland grass which contains only hortensis. We might expect, therefore, that the agreement with background would 
be better in the nemoralis samples than in the hortensis, which may be "diluted" by migration and gene flow from the downland. This appears to be the case. At Kingstone Coombes the wood is surrounded by downland containing only nemoralis, and here the nemoralis sample is aberrant (tending to the grassland type) while the hortensis ample is not. The same is true of Rockley, Manton and Hackpen Woods, although at Rockley and Manton the vegetation outside the woods is more heterogeneous, and at Hackpen nemoralis are scarce on the downland. Apart from such individual peculiarities, one further point demands comment. Among the collections there is a group of downland samples which show a relatively low proportion of yellows and a high proportion of pinks (e.g. Charlbury Hill, Dragons Hill I, 3 and 4 ). The backgrounds from which these samples were taken, however, are not obviously different from other downland backgrounds. Cain (1953) has suggested that the high frequency of pink shells in certain grassy habitats may be due to predation by small mammals, which are colour-blind. Pink shells, if they are scored by tone rather than colour, match a background of grass more closely than do the yellows. I have not been able to estimate the relative importance of mammal and thrush predation in the localities studied, although both types are found in most places. Thrushes do, however, appear to be rarer on open downland than they are elsewhere. Colquhoun and Morley (I94I) in their survey of downland birds, did not record any thrushes in the White Horse Hill area. Thrush-stones, however, do occur.

\section{CORRELATIONS BETWEEN SPECIES}

From the data summarised in figs. $I-3$ it is clear that in both nemoralis and hortensis the distribution of phenotypes is influenced by the nature of the habitat. There is good evidence that this influence operates through the activities of visual predators. Lamotte (195 I, 1959). however, has argued against the importance of visual selection in French colonies of Cepaea. He reasoned that if predation were important in determining the proportions of phenotypes, the two species should show parallel variation, but he found no correlation in mixed colonies between the percentage of unbanded shells in nemoralis and the percentage of the same form in hortensis. There was only a very slight correlation between the percentages of yellows. Cain and Sheppard (I954, I96I) argue that these results do not necessarily contradict the hypothesis of visual selection. They point out that the consequences of visual predation may be influenced by the non-visual selective values of the various phenotypes, values that are unlikely to be the same in both species. This interpretation has been supported by my own results (1960, and above).

If the differences between the two species are taken into account, then we may expect that in mixed colonies there will be a positive correlation between the frequency of yellow "effectively unbanded" shells 
in hortensis and the frequency of yellow shells in nemoralis. A glance at figs. 2 and 3 will demonstrate that this should be so.

Fig. 4 is a scatter-diagram showing the relation between these two proportions. It is evident that the expected relation does not occur. There is no correlation between per cent. yellow "effectively unbanded" hortensis and per cent. yellow nemoralis. Nevertheless, there is a very good separation between habitat classes, better than that obtained with either species alone. Excepting the collection from

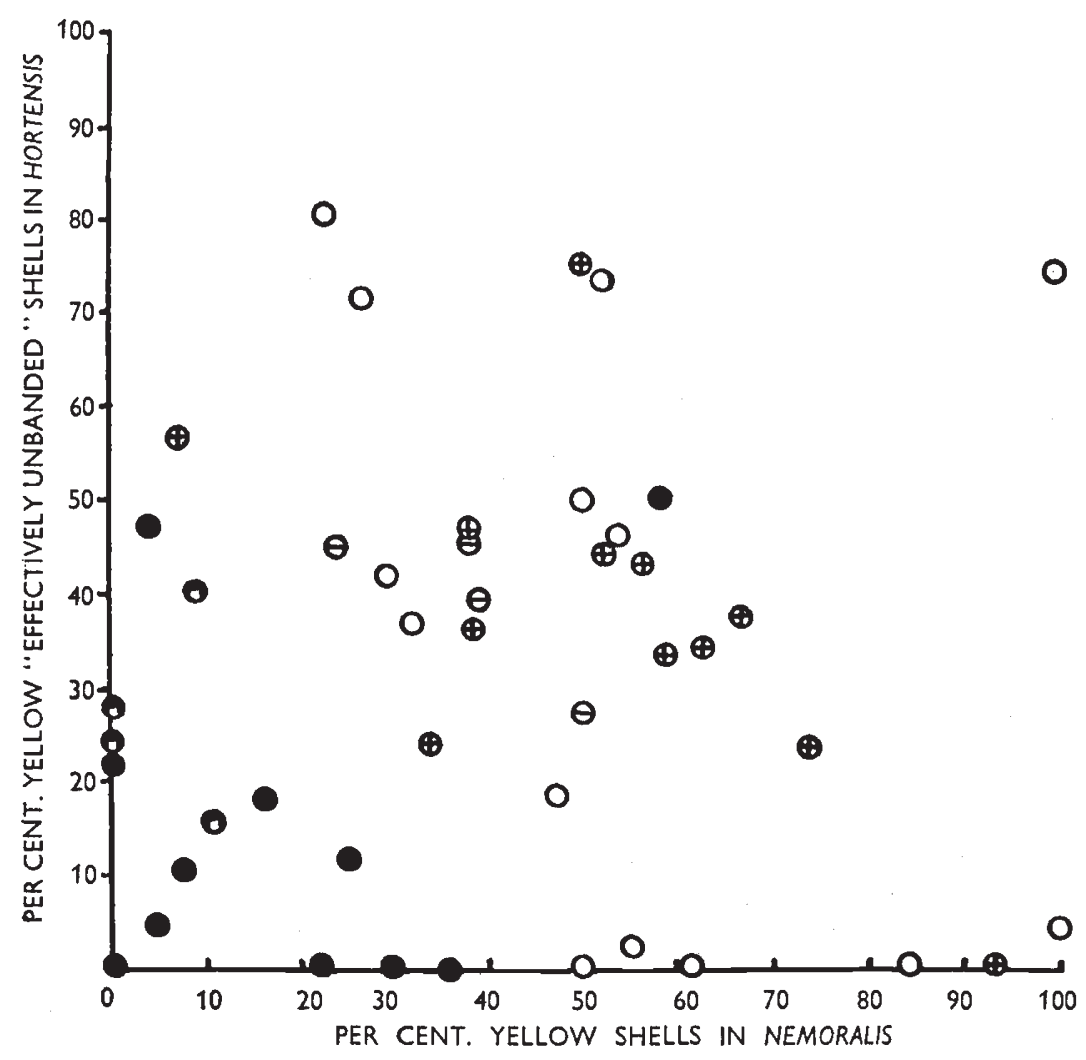

Fic. 4.-A scatter-diagram showing the relation between the percentage of yellow "effectively unbanded" shells in C. hortensis and the percentage of yellow shells in C. nemoralis. Data from samples of mixed colonies. There is a clear separation between "dark" and "light " habitats. Within each broad class of habitats there is a negative relation between the two species. Symbols as in fig. I.

Knoll Down $B$, there is no overlap between the woods and the open habitats. It has already been pointed out that Knoll Down B is the most grassy of the woodlands.

Far from there being a positive correlation between the proportions plotted on fig. 4, it appears that within each of the two broad habitat classes (woods, open habitats) there is a negative correlation. There are some difficulties in testing the significance of these correlations, firstly because of the binomial character of the data, and secondly because the sample sizes are not the same on the two 
axes. I am therefore particularly grateful to $\mathrm{Mr} \mathrm{M}$. H. Quenouille for suggesting the following treatment, which involves a weighted correlation coefficient.

If, at any locality, $x$ is the proportion of yellow "effectively unbanded "shells in hortensis, $y$ is the proportion of yellow shells in nemoralis, and if the sample size of hortensis is $n$ and the sample size of nemoralis is $m$, then the variances of $x$ and $y$ will be, approximately, $x(\mathrm{I}-x) / n$ and $y(\mathrm{I}-y) / m$. The variance of a point representing one locality $(x, y)$ may be taken as $\frac{x(\mathrm{I}-x)}{n}+\frac{y(\mathrm{I}-y)}{m}$. The reciprocal of this is the weight to be attached to the point.

Thus if:

$$
\frac{\mathrm{I}}{\mathrm{W}}=\frac{x(\mathrm{I}-x)}{n}+\frac{y(\mathrm{I}-y)}{m}
$$

and

$$
\begin{aligned}
& \mathrm{G}=\Sigma w x y-\frac{(\Sigma w x)(\Sigma w y)}{\Sigma w} \\
& \mathrm{X}=\Sigma w x^{2}-\frac{(\Sigma w x)^{2}}{\Sigma w} \\
& \mathrm{Y}=\Sigma w y^{2}-\frac{(\Sigma w y)^{2}}{\Sigma w}
\end{aligned}
$$

then $r=\frac{C}{\sqrt{X Y}}$, and $r$ is a correlation coefficient based upon as many pairs of observations as there are localities. It appears that $r$ is fairly insensitive to errors in $w$, but in order to avoid large errors it has been necessary, when calculating weighting coefficients for samples in which any character is absent, to pretend that at least one shell displaying the character occurs in each sample.

On fig. 4 there is no evidence of heterogeneity between the class of grasslands and the class of hedgerows and rough herbages. Nor is there heterogeneity between either of these classes and the fens. It seems legitimate, in calculating the correlation, to consider all of them together as one large group (the open habitats). Using the method just described, it is found that within this group there is a highly significant negative correlation between per cent. yellow "effectively unbanded" (YEU) hortensis and per cent. yellow nemoralis $(r=-0.660 ; p<0.001)$. Among the woods, excluding Knoll Down $\mathrm{A}$ and $\mathrm{B}$, there is also a negative relation, although in this case it is not significant $(r=-0.474 ; p<0 \cdot 1)$.

Fig. 4 does not, of course, compare the frequencies of visually identical types. Such a comparison is not possible because there are no individual varieties that are common enough in both species. The figure has some biological meaning, however, because each axis represents a scale of decreasing "darkness" for the species concerned (see below).

An alternative treatment compares the proportions of YEU hortensis with the proportions of the same category in nemoralis. It is 
not necessarily more meaningful than that shown on fig. 4. Yellow " effectively unbanded" hortensis are usually either unbanded or albino. In nemoralis, however, albinos are very rare, unbanded forms are less common than in hortensis, and the YEU shells are most often 00300 and 00345 (see tables I-3). Nevertheless, once again there is a significant negative correlation among the open habitats $(r=-0.430 ; p<0.02)$ and a non-significant negative correlation among the woods $(r=-0.454 ; p<0.1)$. The correlations are weaker, however, than those shown on fig. 4 , although not

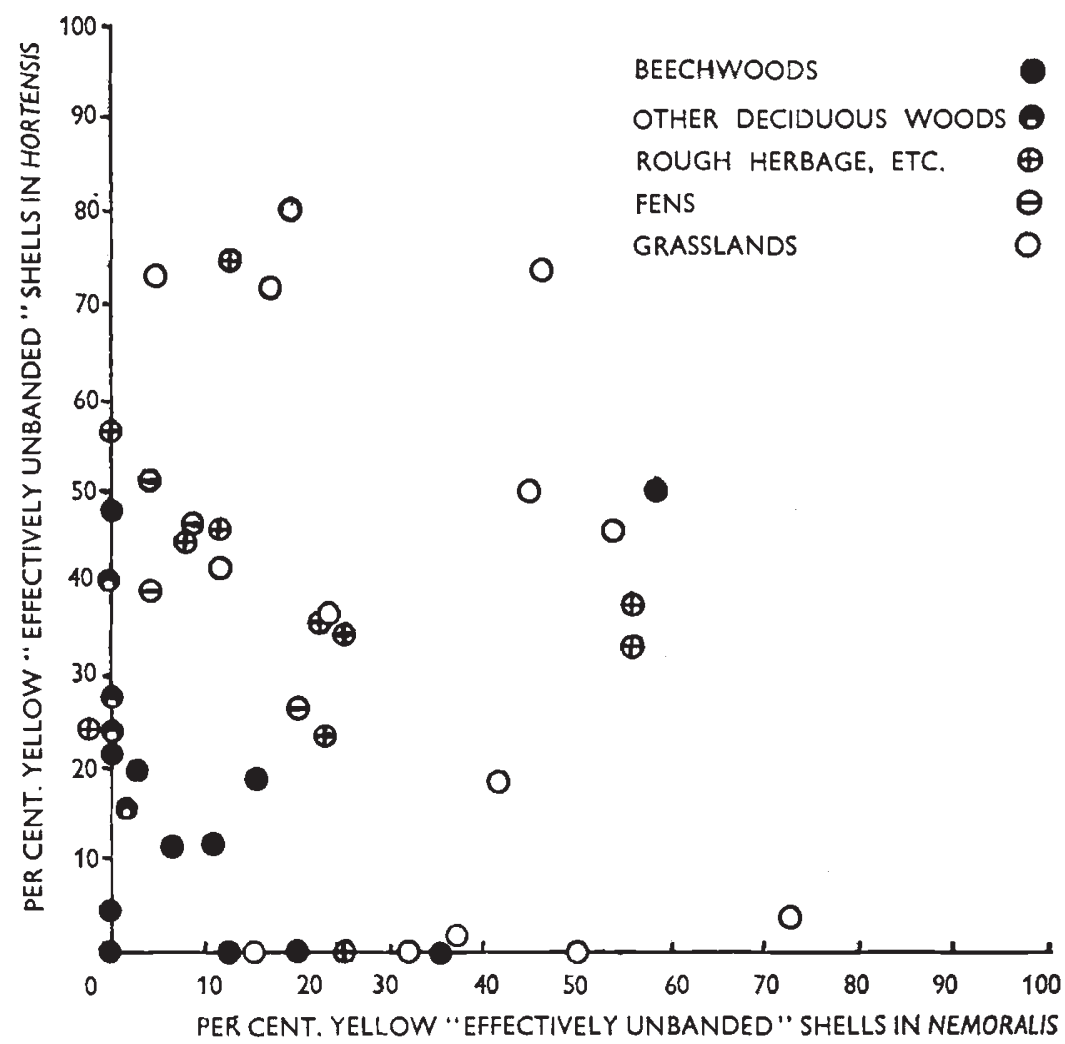

FIG. 5.-A scatter-diagram showing the relation between the percentages of yellow "effectively unbanded" shells in $C$. hortensis and $C$. nemoralis. Data from samples of mixed colonies. The separation between "light" and "dark" habitats is less clear than it is on fig. 4. The negative relations are also less strong.

significantly so, and the separation between habitat classes is less clear (fig. 5).

Another method of comparison considers the proportions of shells that are particularly dark in appearance. Pink and brown shells are grouped with those five-banded yellows that have two or more bands fused together. This form of grouping is also biologically meaningful because it separates "effectively dark" shells from "effectively yellow" (see below). It will be noted that both these groups contain types that are obviously different in appearance. 
Fig. 6 compares the proportions of "effectively yellow" (EY) shells in the two species. It shows an overall positive correlation between them (by the medial test, $p<0 \cdot 00 \mathrm{I})$. There is also a significant positive relation among the woods $(p<0 \cdot 0 \mathrm{I}$, even if Knoll Down A

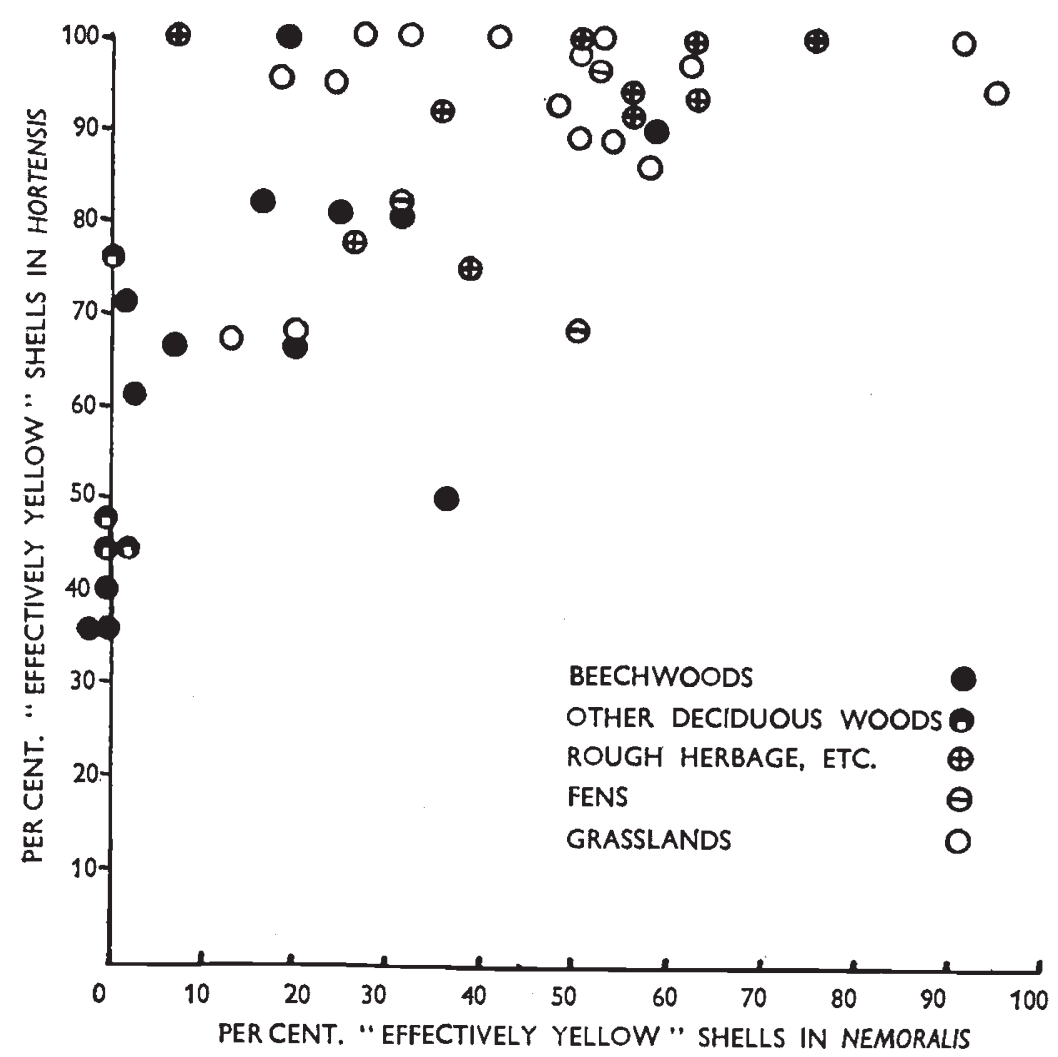

FIg. 6.-A scatter-diagram showing the relation between the percentages of "effectively yellow" shells in $C$. hortensis and $C$. nemoralis. Data from samples of mixed colonies. There is a clear separation between "dark" and "light" habitats, and an overall positive correlation between the frequencies in the two species.

and $B$ are excluded), but not among the open habitats. The separation between habitat classes is clear and significant on both axes $(p<0 \cdot 001)$.

\section{DISCUSSION}

Fig. 6 suggests the action of visual selection. In general, samples from the darker habitats display fewer "effectively yellow" (EY) shells than do samples from lighter and more open habitats. The positions of samples on the figure roughly correspond to the visual properties of their backgrounds. This holds true for the aberrant habitats mentioned above.

The observations summarised in figs. 4 and 5 , on the other hand, contradict simple predictions made on the basis of the hypothesis that visual selection is important in determining the distribution of 
phenotypes in both species independently. Nevertheless, they indicate the action of some form of selection. The very significant separation between woods and open habitats can be due only to this cause.

In the following discussion, an attempt will be made to resolve the apparent contradictions between figs. 4, 5 and 6 . It will be argued that the only satisfactory explanation demands an interaction between the polymorphisms of the two species, and that this interaction results from certain peculiarities of predator behaviour. It is first necessary, however, to consider some alternative possibilities.

The negative correlations shown on figs. 4 and 5 are either accidental results of the sampling procedure, or they are brought about by natural selection. It would be possible for a significant relation to occur as a result of geographical (or microgeographical) grouping of samples. If, for example, half the collections were taken from an area in which yellow nemoralis were common and yellow EU (" effectively unbanded") hortensis were rare, and half were taken from a region in which the frequencies were reversed, this might give rise to an apparent negative correlation. It is very unlikely that this sort of explanation is valid. Although samples which come from adjoining habitats are usually similar in composition, drastic changes of phenotype-frequency can take place over short distances (a hundred yards or less). Some collections from neighbouring localities (e.g. Dragons Hill, White Horse Hill) appear at opposite extremes of fig. 4. Conversely, collections from widely separated localities may have similar phenotypic constitutions in both species (e.g. Little Hinton I and Watchfield; Shepherd's Rest 2 and White Horse Hill 2). If the open habitats are separated into rough geographical groups there is still evidence of negative relations within these groups. The non-significant negative relation among woodland samples also suggests once again that the pattern is not fortuitous. The evidence favours an explanation in terms of natural selection.

Polymorphism in Cepaea is almost certainly balanced, rather than transient. Cain and Sheppard (1954) suggest that its maintenance is due, at least in part, to the selective advantages of heterozygotes at each locus. Heterozygote advantage could not be due to the visible appearance of the shells because the colour and banding genes exhibit complete, or nearly complete, dominance. Thus Cain and Sheppard's interpretation requires the existence of strong non-visual selective forces acting to maintain equilibrium in spite of heavy directional selection by visual predators.

The negative correlations within habitat classes could be due to non-visual selection sufficiently strong to overcome the effects of visual predation. Sedlmair (1956) has reported differences in survival between various phenotypes of nemoralis and hortensis. She found that under the conditions of her experiments the mortality of yellow nemoralis was greater than that of pink. Under similar conditions selection acted against yellow hortensis, and in this species the mortality 
of yellow unbanded forms was found to be greater than that of yellow banded. Boettger (1954), on the other hand, reported experiments in which yellow unbanded hortensis were more viable than the banded forms. Lamotte (1959) repeated Boettger's methods, using nemoralis, and found a preferential survival of yellow shells. Experimental data therefore suggest that conditions favouring yellow nemoralis also favour yellow unbanded hortensis, a conclusion once again in contradiction to the observations reported above.

Heterozygote advantage is not the only means by which a polymorphism can be maintained. A state of balance will result if the genotypes concerned become advantageous when rare and disadvantageous when common. Clarke (196I) has collected evidence that birds and other predators tend to kill a disproportionately low percentage of rare ones. This was first suggested as a possibility by Cain and Sheppard (1954) and Haldane (1955). It seems that predators concentrate on only one or a few varieties at a time and that by a sort of learning process they adopt "specific searching images" for these varieties, tending to overlook other prey even if these are obvious (Tinbergen, 1960). Such behaviour could maintain a colour or pattern polymorphismin the species preyed on, even if heterozygotes at the loci concerned were not favoured by selection. Polymorphisms maintained in this way have been termed apostatic polymorphisms because they involve the selective advantage of phenotypes that stand out from the norm (Clarke, 196r).

It has been suggested that Cepaea polymorphism is at least partly apostatic (Clarke, I96I). The data on hortensis given in this paper lend support to this hypothesis. If the intensity of visual selection did not alter with phenotype-frequency, we would expect not only that the palest and most open habitats would show a high proportion of yellow unbanded shells (as they do), but also that in such habitats those banded forms which do occur would tend towards "palebandedness" or albinism. In fact, as I have already pointed out, it is the colonies with the lowest proportions of yellow unbanded shells that show the highest proportions of albinos and pale-banded forms.

It seems, therefore, that for any particular locality there is an optimum frequency of visibly pale and uniform shells (or conversely, of dark, banded shells), and that visually similar but genetically different varieties may contribute to the attainment of this optimum. Visual selection would not favour deviations from it in either direction. In other words, something like apostatic selection is indicated.

I am grateful to Drs A. J. Cain and P. M. Sheppard for pointing out that the same sort of situation is found in their samples of $C$. nemoralis. If the combined frequencies of 00000 , 00300 and 00345 shells (i.e. "effectively unbanded" forms) is plotted for each locality, there is a better separation between habitat classes, and a more compact grouping within them, than there is if the frequency of any of these forms is plotted alone. Once again this suggests that there 
are optimum frequencies for particular visual types at particular localities. The data given in this paper are not in agreement with Cain and Sheppard's observations, since a slightly better separation between habitat classes is obtained if the frequency of oozoo alone is plotted. The earlier observations, however, cover a far larger number of samples and must be given greater weight.

It is worth noting that apostatic selection could be responsible for the " hierarchy of dominance" found by Cain, King and Sheppard (1960) in Cepaea nemoralis. It does not seem necessary to postulate, as they do, that the polymorphism of nemoralis " mimics" the heterogeneity of the habitat backgrounds. Some of the varieties of this species appear to stand out against all backgrounds (e.g. bright pinks, some forms of 00300, etc.). Yellow unbanded shells certainly match no component of the background in pure beechwoods although they are found in them. Furthermore, a re-analysis of Popham's (194I, 1942) data by Clarke (I96I) indicates that apostatic selection can take place in a perfectly uniform habitat.

When two sympatric species share the same predator, and when conditions are favourable to selection for apostasy, the two forms will diverge in appearance. If the predator has a "searching image" for one species, selection on the other will favour variants that have the least likelihood of being confused with it. If both species are polymorphic, and if the polymorphisms are homologous, then we may expect that selection will act in one species against any variety that is common in the other. If, for example, yellow "EU " shells are particularly common in $C$. hortensis (because, perhaps, of selection unrelated to their visible properties) we should expect an unusually low frequency of the form in $C$. nemoralis. The properties of the background will, of course, determine what frequencies are to be considered "unusually" high or low. A balance due to apostatic selection would not prevent response to the visual quality of the habitat.

This can be put in another way. I have already pointed out that the two species are very similar. If the predator cannot effectively distinguish between them, it must behave as if there is only one, in which one polymorphism is being maintained. The point of balance will depend upon the nature of the background and the visibility of the different varieties against it. The non-visual selective values of the phenotypes concerned will determine which species contributes the majority of any one of them, but if either species shows a high proportion of one variety, there will be selection against it in the other species.

Against visually extreme backgrounds, the " apostatic equilibrium point " may be such that both species show a high proportion of the same phenotype. Nevertheless, in general, we should expect a negative relation between the frequencies of similar forms in the two species. Fig. 5 shows just such a relation. 
The apparent contradictions between figs. 4, 5 and 6 can now be resolved if the visual properties of the various phenotypes are taken into consideration. They can be arranged approximately in order of increasing darkness as follows:

I. Yellow "effectively unbanded" (YEU)

2. Yellow "effectively banded" (YEB)

3. Yellow five-banded with fusions (YBF)

4. Pink "effectively unbanded" (PEU)

5. Pink "effectively banded" (PEB)

6. Pink five-banded with fusions (PBF)

7. Browns (B)

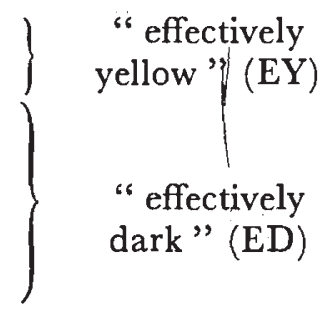

To the human eye these categories do not represent uniform steps of increasing darkness. There is no reason to suppose that the human eye differs greatly in this respect from the eye of the thrush or of any other predatory bird (Pumphrey, 1948; Kettlewell, 1955). The ordering of categories 3,4 and 5 is arbitrary. In populations where pink shells are pale, category 3 is darker than 4 or 5 . In all populations, however, the sharpest tonal discontinuity seems to lie between categories 2 and 3. YEU and YEB shells are both clearly yellow, but complete fusion of the bands transforms a yellow shell to one that is effectively brown. There are, of course, different degrees of band-fusion. Two, three, four or five bands may be involved, and the visual effect will depend upon the position of the bands concerned. I have found, however, that the proportions of different types of fusions tend to be positively correlated with each other (Clarke, in preparation) and that the arbitrary grouping of all types of fusions into one category has no significant effect upon the associations to be discussed. Category 3 can be considered, with pinks and browns, to be " effectively dark". There is justification also for grouping categories I and 2 together as " effectively yellow". In many habitats, particularly those with a heterogeneous or striped background, it is difficult to decide whether YEU or YEB shells are the more cryptic. It is only in the most uniform pale grassy habitats that YEU seem to be superior. In dark habitats, of course, YEB are more cryptic than YEU.

It is reasonable to expect that simple visual selection for crypsis will operate most strongly at the point of maximum tonal discontinuity (i.e. between EY and ED). The positive correlation between the percentages of EY will then be the result of the fact that both these percentages are related to the precise visual character of the background. If simple selection for crypsis is ever strong enough to obscure the effects of apostatic selection (or of any other selection tending to produce negative correlations between the percentages of visually similar phenotypes), it will do so at the level of the EY/ED discontinuity. This is the more likely because both the EY and the ED classes contain several visually distinct (but cryptically nearly equivalent) types.

Since, within the EY class, the cryptic advantages or disadvantages 
of YEU and YEB are never very greatly different, selection for crypsis is less likely to obscure the effects of apostatic (or other) selection. The results given on figs. 4,5 and 6 are therefore consistent with the hypothesis that both types of selection are operating simultaneously.

If the percentages of YEB shells in the two species are plotted against each other no correlation, either negative or positive, is found. The YEB class is totally absent in all my samples of nemoralis from woods. The lack of a correlation among open habitats, where YEB shells occur in both species, seems at first sight to argue against apostatic selection. It has already been suggested, however, that in some colonies the proportions of banded shells are above the "apostatic optimum ", and that in these colonies there is an appreciable frequency of pale-banded shells in hortensis. If all samples showing more than Io per cent. pale-banded forms are excluded from consideration, then the proportions of YEB in the two species are found to be negatively correlated, although not significantly so.

YBF shells are extremely rare among woodland nemoralis. In none of my woodland samples does their frequency exceed 5 per cent., and in twelve out of the sixteen samples they are absent. Among the open habitats there is a non-significant negative relation between the proportions of YBF shells in the two species. The two colonies that deviate most strongly from this negative relation are Stanford in the Vale and the Ham. It has already been remarked that their backgrounds are unusually dark.

There is a significant positive correlation (by the medial test, $p<0 \cdot 001$ ) between the two species in the percentage of fusions among five-banded shells (regardless of colour). This is presumably another result of the overall selection for crypsis that is responsible for the positive relation between percentages of EY. In the darker habitats fusions are favoured. In nemoralis, fusions are usually commoner among pink shells than they are among yellow.

The percentages of unbanded shells in the two species appear to be unrelated. There is a slight positive correlation, not significant, between the percentages of yellow shells. These results agree with the observations of Lamotte (195 I, 1959), who studied mixed colonies in France. Lamotte, however, interpreted his findings as evidence that visual selection was of minor importance in determining the frequencies of such phenotypes. The complex and significant correlations already described do not support this interpretation.

Sheppard (quoted by Ford, 1955) has pointed out that once a polymorphism has arisen, heterozygote advantage is likely to evolve. It is to be expected that apostatic selection will not be alone in maintaining diversity in Cepaea.

\section{CONCLUSIONS}

The observations described in this paper support the hypothesis that natural selection is an important factor in determining the 
frequency of phenotypes, and therefore of genotypes, in both species of Cepaea. They provide further evidence that visual predation is a major component of this selection. Grouping the various phenotypes according to their visual characters gives the clearest relation between the composition of a sample and the type of habitat from which it was taken. Positive correlations between the two species are found among groups of phenotypes on which visual selection for crypsis is expected to be strong. Negative correlations can be interpreted as being due to apostatic selection, which would result from a tendency by predators to kill a disproportionately large number of common varieties of prey and a disproportionately small number of rare ones.

It is possible, however, to suggest an explanation of the observations that does not involve the hypothesis of apostatic selection. This necessitates some form of non-visual selection that acts to favour yellow unbanded hortensis when yellow unbanded nemoralis (perhaps all yellow phenotypes of this species) are disfavoured-and vice versa. It has been pointed out that the results of experiments on non-visual selection in Cepaea argue against this possibility, and that an explanation which excludes apostatic selection, or something like it, fails to account for the apparent occurrence in both species of "visual optima " to which a number of genetically different but visually similar phenotypes may contribute. Furthermore, apostatic selection provides the most satisfactory explanation of the origin and maintenance of distinct visual types in populations of Cepaea (Clarke, I96I). The evidence, although not conclusive, favours the hypothesis of apostatic selection.

It seems likely that the following forces of selection act upon Cepaea populations:

(1) Non-visual selection acting differentially upon the two species, and perhaps rendering the heterozygotes advantageous at many of the loci.

(2) Visual selection by predators for crypsis.

(3) Apostatic selection, acting to bring about inverse relations between groups of visually similar phenotypes, and, within individual species, contributing to the maintenance of polymorphism.

\section{SUMMARY}

I. Random samples were collected from a number of mixed colonies of the polymorphic land snails Cepaea nemoralis L. and Cepaea hortensis Mull. Shells were scored for age, condition, colour and banding.

2. Analysis shows that the proportions of certain varieties in both species can be related to the type of habitat from which the samples were taken. There is good evidence that the statistically significant differences between habitat classes are due to the action of natural selection, particularly of visual selection by predators. The two species respond to such selection in different ways.

3. There is evidence that predators, under certain circumstances, 
act to maintain polymorphisms in species preyed on. They kill a disproportionately large number of common varieties, and a disproportionately small number of rare ones. Polymorphisms maintained in this way have been called apostatic polymorphisms because they involve the selective advantage of phenotypes that are rare and unusual.

4. In both nemoralis and hortensis there appear to be optimum frequencies for particular visual types at particular localities. It seems that visually similar but genetically different varieties may contribute to the attainment of these optima. This suggests that the selective value of a phenotype may depend upon its frequency.

5. If two polymorphic species share the same predator, and if conditions are favourable to apostatic polymorphism, then it is to be expected that selection will act in one species against any variety that is particularly common in the other. In a series of mixed populations from roughly similar habitats, this should produce a negative relation between the frequencies of visually similar forms in the two species.

6. Among samples from open habitats (grasslands, fens, rough herbage, etc.) there is a significant negative correlation between the frequency of yellow "effectively unbanded" shells in hortensis and the frequency of the same variety in nemoralis $(p<0.02)$. Among samples from woods there is a non-significant negative correlation $(p<0 \cdot \mathrm{I})$. There are also non-significant negative relations between the two species in the proportion of yellow " effectively banded", and of banded yellow shells with fused bands.

7. There is an overall positive correlation $(p<0.00 \mathrm{I})$ between nemoralis and hortensis in the frequency of "effectively yellow" shells.

8. A number of other correlations between the species are discussed.

9. The observed relations between the two species suggest the action of visual selection for both crypsis and apostasy. This interpretation demands, in addition, the action of non-visual selection.

Acknowledgments.-I am very grateful to $\mathrm{Dr}$ A. J. Cain, who has generously given his help at all stages of the work. Dr D. Falconer, Dr E. B. Ford, F.R.s., Dr H. B. D. Kettlewell, Mr J. J. Murray, Dr P. M. Sheppard, Dr M. H. Williamson and my wife have all been generous in their assistance, discussion and criticism. I am indebted to Mr M. H. Quenouille, Dr A. Robertson and Dr B. Woolf for statistical advice, although they are not responsible for the results of it. Thanks are also due to Miss J. Libberton for drawing the diagrams. The greater part of the work was carried out during the tenure of a Nature Conservancy Research studentship at the Department of Zoology, Oxford. I am very grateful to Professor Sir Alister Hardy, F.R.s., for the help and facilities he has provided.

\section{REFERENCES}

BOETTGER, C. R. 1954. Zur Frage der Verteilung bestimmter Varianten bei der Landschneckengattung Cepaea Held. Biol. Zbl., 73, 318-333.

CAIN, A. J. I953. Visual selection by tone in Cepaea nemoralis L. F. Conch., 23, 333-336. 
CAIN, A. J., King, J. M. B., AND Sheppard, P. M. 1960. New data on the genetics of polymorphism in the snail Cepaea nemoralis L. Genetics, 45, 393-4I I.

CAIN, A. J., AND Sheppard, P. M. 1950. Selection in the polymorphic land snail Cepaea nemoralis. Heredity, 4, 274-294.

Cain, A. J., ANd sheppard, P. M. 1954. Natural selection in Cepaea. Genetics, 39, 89-II 6 .

CAIN, A. J., AND Sheppard, P. M. 1957. Some breeding experiments with Cepaea nemoralis L. F. Genet., 55, 195-199.

CAIN, A. J., AND Sheppard, P. M. rg6r. Visual and physiological selection in Cepaea. Amer. Nat., 95, 6I-64.

CLARKE, B. C. 196o. Divergent effects of natural selection on two closely-related polymorphic snails. Heredity, 14, 423-443.

CLARKE, B. C. 196r. Balanced polymorphism and the diversity of sympatric species. In Taxonomy and Geography, ed. D. Nichols, Syst. Ass. Pub. No. 4 (in press).

COlquhoun, м. K., AND MORLEy, A. M. 1941. The density of downland birds. $\mathcal{F}$. Anim. Ecol., 10, 35-46.

FORD, E. B. I955. Rapid evolution and the conditions which make it possible. Cold Spr. Harb. Symp. Quant. Biol., 2o, 230-238.

HALDANE, J. B. s. 1955. On the biochemistry of heterosis, and the stabilisation of polymorphism. Proc. Roy. Soc. B, 144, 21 7-220.

KETTLEWELL, H. B. D. I955. Selection experiments on industrial melanism in the lepidoptera. Heredity, 9, 323-342.

LAMOTTE, M. I951. Recherches sur la structure génétique des populations naturelles de Cepaea nemoralis (L.). Bull. Biol. Suppl., 35, r-239.

LAмотте, M. I954. Sur la déterminisme génétique du polymorphisme chez Cepaea nemoralis L. C.R. Acad. Sci., 239, 365-367.

LAмотте, м. 1959. Polymorphism of natural populations of Cepaea nemoralis. Cold Spr. Harb. Symp. Quant. Biol., 24, 65-86.

POPHAM, E. J. I94 I. The variation in the colour of certain species of Arctocorisa (Hemiptera, Corixidae) and its significance. Proc. Zool. Soc. Lond. A, III, I 35-I 72.

POPHAM, E. J. 1942. Further experimental studies on the selective action of predators. Proc. Zool. Soc. Lond. A, II2, $105^{-1} 17$.

PUMPHREY, R. J. 1948. The sense organs of birds. Ibis, go, 1 7 1-190.

sEDlmair, H. 1956. Verhaltens-, Resistenz- und Gehauseunterschiede bei den polymorphen Bänderschnecken Cepaea hortensis Mull., und Cepaea nemoralis L. Biol. Zbl., 75, 281-313.

SCHILder, F. A. 1950. Die Ursachen der Variabilitat bei Cepaea. Biol. Zbl., 69, 79-103.

SCHNETTER, M. 1950. Veränderungen dergenetischen Konstitution in naturlichen Populationen der polymorphen Bänderschnecken. Verh. Deut. Zool. Marburg., 1950, 192-206.

SHEPPARD, P. M. 1951. Fluctuations in the selective value of certain phenotypes in the polymorphic land snail Cepaea nemoralis L. Heredity, 5, I25-134.

taylor, J. W. 1914. Monograph of the Land and Freshwater Mollusca of the British Isles, 3. Taylor, Leeds.

TINBERGEN, L. 1960. The natural control of insects in pinewoods. I. Factors influencing the intensity of predation bỵ song-birds. Arch. Néerl. Zool., 13, $265 \cdot 336$. 